\title{
Ultrasound for Critical Care Physicians: Shortness of Breath
}

\author{
Matthew JK Douglas, MD \\ David Verbunker, MD \\ Jarrod Mosier, MD
}

Department of Emergency Medicine

Banner University Medical Center Tucson

University of Arizona

Tucson, AZ

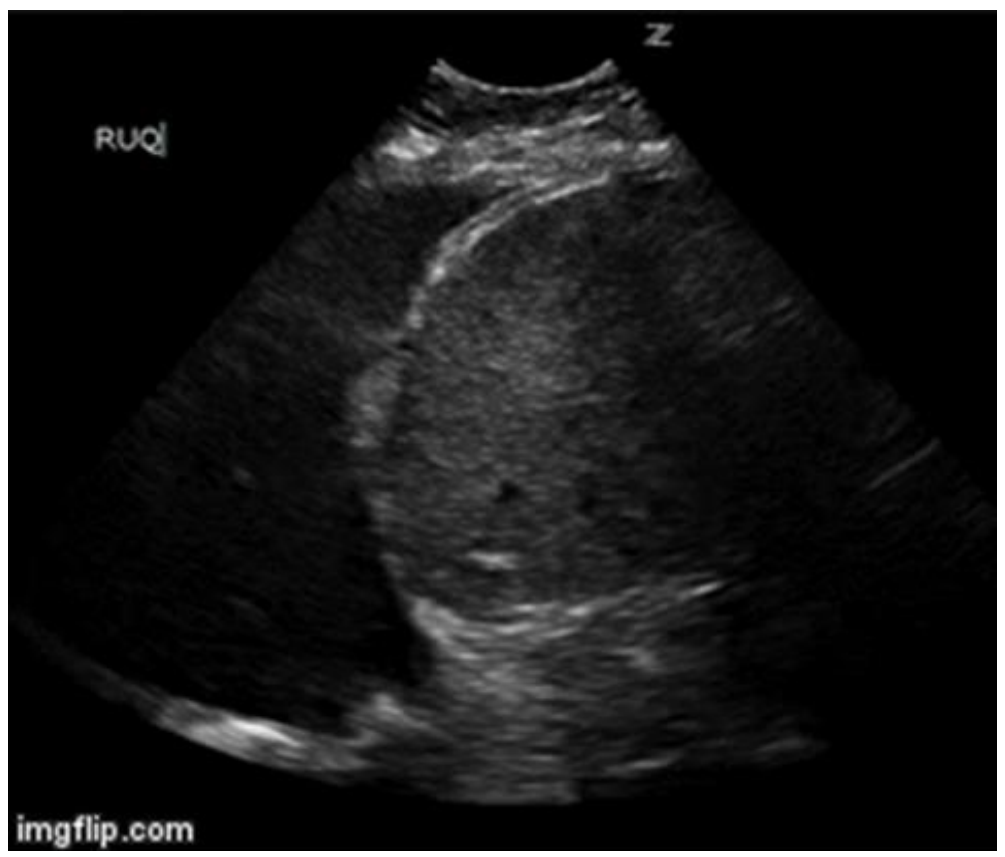

Figure 1. Still image of the right thoracic ultrasound (coronal).

An 85 year old woman with a history of congestive heart failure and diabetes presented to the emergency department with progressive shortness of breath. She had recently been discharged from another hospital where she had been admitted for several days for community acquired pneumonia. The patient was in respiratory distress on arrival with tachypnea, increased work of breathing, and hypoxia despite supplemental oxygen with a non-rebreather mask and she was subsequently intubated. ED point-of-care ultrasound was performed of the right hemithorax.

\section{What does Figure 1 demonstrate?}

1. Intravascular volume depletion

2. Normal lung aeration

3. Numerous B-lines

4. Pleural effusion and consolidation

5. Pneumothorax 


\section{Correct! \\ 4. Pleural effusion and consolidation}

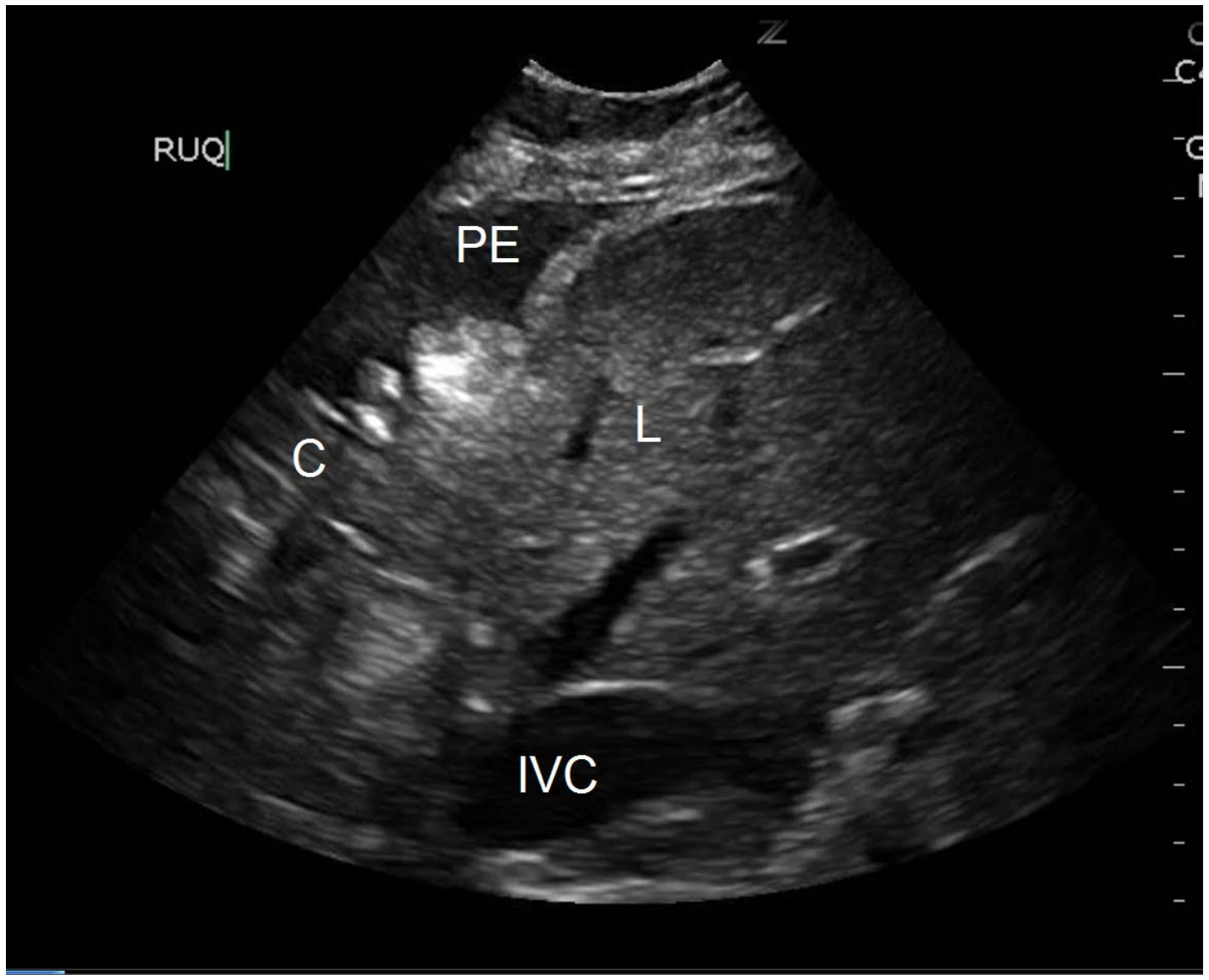

Figure 2. Still image from figure 1 labeled with pleural effusion (PE), consolidation (C), liver (L), and inferior vena cava (IVC).

The lung ultrasound reveals lung hepatization (Figures 1 and 2) or consolidation resulting from a likely pneumonia. While the chest $x$-ray and thoracic CT were obtained which were felt to be more consistent with pulmonary edema, a diagnosis of pneumonia was suspected and antibiotics were begun. Broad spectrum antibiotics were initiated, central access was obtained and vasopressors initiated as the patient developed hypotension, and the patient was rapidly admitted to the ICU. Subsequent chest x-rays obtained while in the ICU were more consistent with pneumonia, highlighting the increased sensitivity of ultrasound in diagnosing pneumonia and its utility in the emergency department and ICU (1) .

\section{Reference}

1. Bourcier JE, Paquet J, Seinger M, Gallard E, Redonnet JP, Cheddadi F, Garnier D, Bourgeois JM, Geeraerts T. Performance comparison of lung ultrasound and chest X-ray for the diagnosis of pneumonia in the ED. Am J Emerg Med. 2014;32(2):115-8. [CrossRef] [PubMed] 